\title{
Geoscience and the two-degree world
}

\section{Michael Stephenson reports on the 2019 Bryan Lovell meeting, where geoscientists, social scientists and policy makers met to offer geological solutions to the 'well below $2{ }^{\circ} \mathrm{C}$ ' objective agreed at the COP21 conference in Paris}

At the 2015 United Nations international climate change conference in Paris (COP21), 195 countries committed to limit global warming to well below $2^{\circ} \mathrm{C}$ compared to pre-industrial levels. But current plans and pace of progress are still far from sufficient to achieve it. The Bryan Lovell Meeting (https:// www.geolsoc.org.uk/GSL-BryanLovell-2019), held in London in January 2019, brought together delegates from across the world to discuss geological decarbonisation-or ways that geoscience and the subsurface can contribute to global efforts to keep global warming well below $2^{\circ} \mathrm{C}$.

The specific objective of the meeting was to examine the role that geoscience and the subsurface could play in decarbonising electricity production, industry, transport and heating to meet UK and international climate change targets. These technologies vary from direct decarbonisation of electricity production, through carbon capture and storage (CCS), to direct substitution of domestic heating by geothermal, but also include more ambitious technologies, such as bioenergy and carbon capture and storage (BECCS), that aim to achieve negative emissions. The supply of geological materials that we'll need in the future to sustain the electrification of the vehicle fleet and other low-carbon technology was also discussed. The conclusion of one hundred delegates gathered in Burlington House was that geoscience has a lot to offer, but that we as a community need to better organise and influence-to make sure the voice of geoscience is heard.

\section{Subsurface heat store}

Several talks focussed on the ground as a heat store. Much progress is being made in Germany by teams led by Ingo Sass (Technische Universität Darmstadt) and Sebastian Bauer (Christian-AlbrechtsUniversity Kiel). In Germany, about 50\% of total energy demand is due to heating as well as cooling, but geological heat storage in the urban subsurface could help in storing solar thermal energy and industrial surplus heat to smooth out supply and demand through the year, from summer to winter.

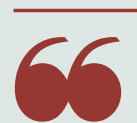

GEOSCIENCE HAS A LOT TO OFFER, BUT WE AS A COMMUNITY NEED TO BETTER ORGANISE AND INFLUENCETO MAKE SURE THE VOICE OF GEOSCIENCE IS HEARD

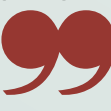

\section{CCS}

Perhaps most discussion time was dedicated to carbon capture and storage. Several speakers, including Martin Blunt (Imperial College London) and Jon Gibbins (University of Sheffield), discussed its implementation, concluding that safe, long-term storage of carbon dioxide in the subsurface is possible with careful site characterization, injection design and monitoring. They also noted that it is current commercial arrangements, not technical difficulties that are holding back large-scale implementation. Whatever the finances, it's likely that the expertise and knowledge of the oil-and-gas companies will be central to a CCS industry roll out.

Clair Gough of the Tyndall Centre (University of Manchester) talked about a variant of CCS explaining how bioenergy and carbon capture and storage (BECCS) has become central to achieving the goal of limiting global average temperature rise to $1.5 \mathrm{C}$. However, Gough concluded that bringing together modern biomass energy systems with CCS at scales large enough to contribute to negative emissions at a global level goes well beyond technical and scientific challenges.

\section{Raw materials}

A good part of the conference was given over to the raw materials we'll need to power and facilitate decarbonisation, for example, materials for batteries for electric cars. Karen Hanghøj (EIT Raw Materials) explained how the key to getting the raw materials we'll need for the energy transition will be a better understanding of the 'circular economy'. That is, bringing raw materials into the loop in a sustainable way, keeping materials in the loop for a long as
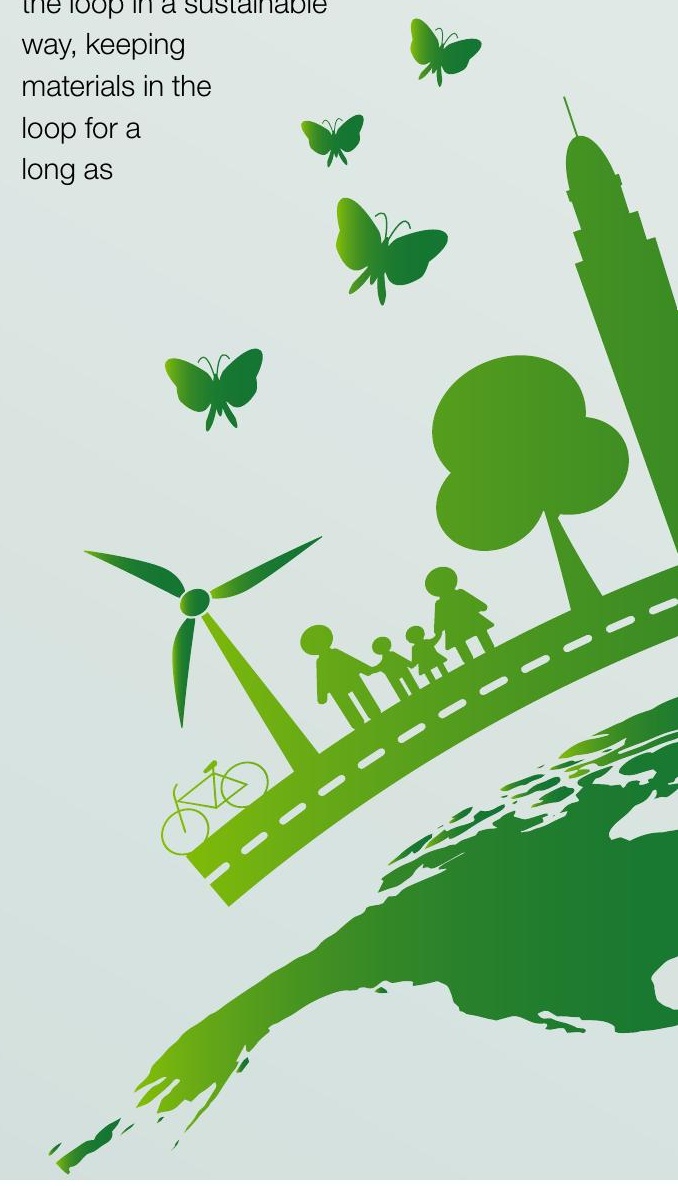
possible, and minimizing waste at all stages.

Frances Wall (University of Exeter) pointed out that however well we recycle and re-use, we'll continue to need to mine materials that are part of solar cells, wind turbines, electric cars, fuel cells and nuclear power stations, simply to meet growing demands and sustain burgeoning populations.

\section{Social context}

For me, the most interesting talk was one by the social scientist Benjamin Sovacool (University of Sussex) who explained the historical context of energy transitions. This echoed my own opening comments of the conference where I noted how geological science, resources and their distribution were part of the 'carbonisation' energy transition that we call the industrial revolution-and that 'decarbonisation' will also need a deep understanding of the subsurface for heat storage, geothermal, CCS and other technologies. Indeed, a talk by Charlotte Adams (Durham University) focussed on the value that the abandoned coal mines of the industrial revolution could have in bringing heat to homes in areas important to the UK's industrial past.

Sovacool's message was that transitions can be excruciatingly slow, but that if you get conditions right, they can be faster.

Perhaps geoscience can help to make the fossil-to-renewables transition faster? To make that happen, we need to step up our research in a concerted way, organise and speak as a group to influence government, industry and the science funders.
Professor Michael Stephenson is Director of Science and Technology at the British Geological Survey, Keyworth; e-mail: mhste@bgs.ac.uk

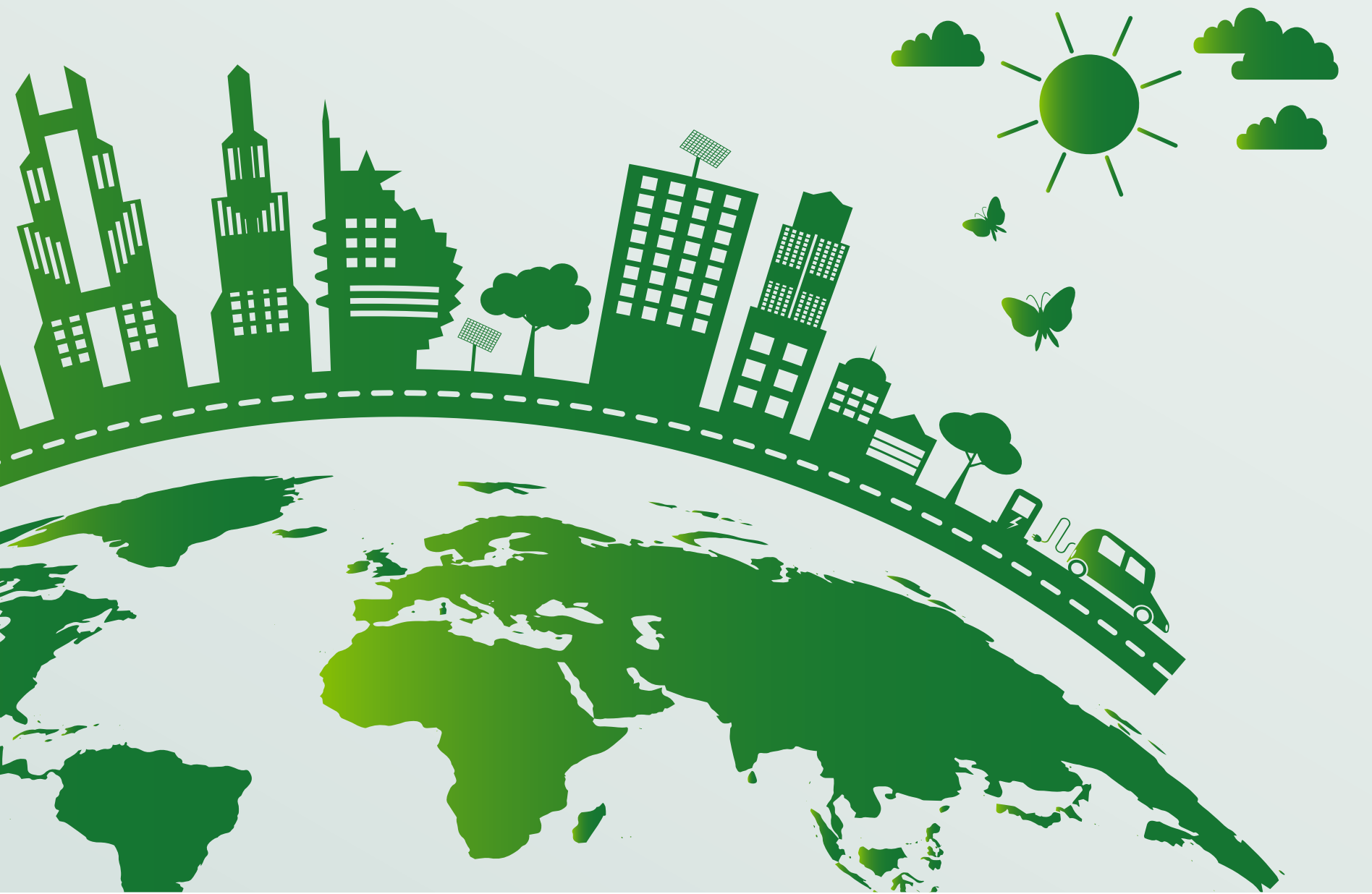

